\title{
A Pragmatic Analysis of the Impact of Cooperative Principle on Outpatient Discourse
}

\author{
Yueyue Liang, Lin Du \\ Shenzhen Clinical School of Medicine, Guangzhou University of Chinese Medicine, Guangzhou, China \\ Email:2101805066@qq.com
}

How to cite this paper: Liang, Y. Y., \& Du, L. (2019). A Pragmatic Analysis of the Impact of Cooperative Principle on Outpatient Discourse. Open Journal of Modern Linguistics, 9, 405-415.

https://doi.org/10.4236/ojml.2019.96033

Received: October 8, 2019

Accepted: November 2, 2019

Published: November 5, 2019

Copyright $\odot 2019$ by author(s) and Scientific Research Publishing Inc. This work is licensed under the Creative Commons Attribution International License (CC BY 4.0).

http://creativecommons.org/licenses/by/4.0/

(c) (i) Open Access

\begin{abstract}
Based on the framework of the Cooperative Principle, the qualitative research method was adopted to analyze the compliance and violation of the Cooperation Principle between doctors and patients in the outpatient departments. The research object of this thesis is the dialogue between doctors and patients in outpatient departments of Chinese hospitals. The corpus of this study was collected by the author in four outpatient departments of a Grade A hospital in Shenzhen in 2019. In this thesis, 20 cases of doctor-patient dialogues were randomly selected from 83 cases of recorded corpus according to proportion of each department, and the following conclusions were drawn: 1) When answering the doctor's question, most patients violate the Maxim of Quantity. 2) Many patients often violate the Maxim of Relevance. 3) Both doctors and patients often comply with the Maxim of Manner. 4) Most doctors often comply with the Maxim of Quality and violate the Maxim of Relevance. This thesis purposes the existing problems in Chinese outpatient conversation, and provides guidance for the doctor-patient communication in the future.
\end{abstract}

\section{Keywords}

Doctor-Patient Interaction, The Cooperative Principle, Discourse Analysis, Chinese Hospitals

\section{Introduction}

The doctor-patient conversation is an important institutional discourse. The characteristic of institutional discourse is that it is guided by the institutional task and the obvious purpose. The task of the outpatient discourse is to help the patients to solve their healthy problems. Language has been affirmed as having an important role in the medical progress (Byrne \& Long, 1976). Every word of the patients can affect the diagnosis given by the doctors and thus doctors will adopt different treatment. Similarly, every word of the doctors can define the pa- 
tients' destiny. A great conversation between a doctor and a patient can help the doctor make accurate and quick diagnosis so that patients can receive proper treatment on time. Conversely, poor communication between a doctor and a patient can cause misunderstanding which may not only worsen the relationship between them, but also delay the diagnosis and put the patient in risked condition (Den Boeft, Huisman, \& Morton, 2017).

Against such a background, the study of conversations between doctors and patients becomes necessary and it still needs theoretical guideline besides the traditional conversation analytic approach. In 1967, an American linguist, Herbert Grice, put forward the Cooperative Principle in his lectures at Harvard. Grice's theories about conversational implication and Cooperative Principle have made great contributions to the linguistic field. It is well known that people often express ideas by implying them rather than saying them directly. Grice used the term "implication" to represent the implied parts in an utterance. In his opinion, what an utterance conveys in context falls into two parts: what is said explicitly and what is implied. What is said is the logical content, the minimum necessary to identify the truth conditions of the sentence. What is implicated is known as implication. Grice tried to understand how people manage to convey implied information. Due to the exploration of the question, we share Grice's four maxims of the Cooperative Principle. According to Grice, our dialogues in our life do not normally consist of a succession of disconnected remarks, and if they did, it would be irrational. They are characteristically cooperative efforts to some degree at least, and each participant of the conversation recognizes a common purpose or set of purposes, or at least a mutually accepted direction (Leech, 1983).

This thesis aims to analyze the Cooperative Principle in doctor-patient oral interaction from the perspective of pragmatics, more exactly, CP-directed analytical classification for doctor-patient interaction, trying to discuss the compliance and violation of Cooperative Principle during the doctor-patient oral interaction in the outpatient department. Therefore, the following questions are to be addressed.

1) In which situation do doctors and patients obey the CP? What is the reason if they don't?

2) What is the effect of the CP on the doctor-patient interaction? Does it have advantage if someone violate the $\mathrm{CP}$ ?

3) How to raise the efficiency between the conversation between doctors and patients in modern hospitals?

Hopefully, the major findings of the study are expected to guide and standardize current doctor-patient communication and to promote the development of better doctor-patient relationship in the future.

\section{Literature Review}

Although both corpora in medical environment and the theory of the Cooperative Principle have attracted certain attention, there are few studies combined 
the two kinds of perspective. Among the studies, most of them are academic dissertation.

Jiang Jin found that violations of the maxim of quality were common for both doctors and patients and suspected that the violation of these maxims undermined the cooperativeness of doctor and patient (Jin, 1999).

Hongwei Li regards that both patients and doctors prefer to follow the $\mathrm{CP}$ as much as possible, and sometimes even sacrifice Politeness Principle to reach the most compliance of the CP (Li, 2006).

Xingbing Liu analyzed the linguistic phenomena of doctor-patient conversation from several aspects and pointed that classic Cooperative Principle could hardly explain some phenomena in the outpatient conversation (Liu, Liu, \& He, 2008). And since classic Cooperative Principle cannot fit all the situation in doctor-patient verbal interaction, it is necessary to build a new cooperative principle on the basis of the classic one.

Xiangqi Zhang collected 600 questionnaires and got the result that doctors would easily violate the maxim of manner while patients would violate the maxim of quality mostly (Zhang, 2015). And another dissertation published by Wei (2015) showed a similar result, but Wei found that most doctors often comply with the Maxim of Quality and violate the Maxim of Quantity (Wei, 2015).

In conclusion, there are only a few researches about outpatient discourse, rarely discussing the impact of the Cooperative. As a result, further efforts can be made in the study of the Cooperative Principle, in the analysis of outpatient discourse, as well as in the application of the CP on the doctor-patient interaction.

Therefore, this article aims to analyze the major pragmatic function of the compliance and violation in outpatient conversations by applying several key notions of the $\mathrm{CP}$.

\section{Method}

\subsection{Subjects}

The main subject of this study is the oral interaction between doctors and patients in outpatient departments of the Chinese hospitals. The entire corpus used in this study is collected by the writer, in January and March in 2019, from four departments in outpatients in a Grade A hospital in Shenzhen. The author selects nine doctors for this study, and five of them are males and four of them are females. These doctors include chief physician and attending doctor. It covers four departments in outpatients, including two departments of internal medicine, department of plastic surgery and department of dermatology. The two departments of internal medicine are respiratory medicine department and endocrinology department. In addition, the patients in this study are of different ages, educational backgrounds and social status.

\subsection{Materials}

This thesis is mainly based on eighty-three doctor-patient oral interactions. The 
place where the author recorded the doctor-patient oral interaction is in the outpatient departments of a Grade A hospital in Shenzhen. The consultations of the outpatient departments took place in different consulting rooms. Every consulting room was separate. Each patient took a numbered voucher from the registration office. The doctor called on the patients to enter the consultation room one by one according to their numbers. All the patients had to wait outside the consultation room until the doctor called them. However, the reality was that when the doctor was treating a patient, usually other patients or the relatives still stayed in the consultation room and sometimes some patients entered the consultation room for for various special problems before they got the voucher.

The corpus collection work has been done by the author by means of pretending to be an intern. The writer did not participate in the interaction and communication between doctors and patients during the process of collecting corpus. The total length of the recorded corpus is about 10 hours. Moreover, the shortest one is 119 seconds and the longest one is 525 seconds. The information includes the names of the departments, and other nonverbal behavior of the doctors and patients, for example, the body languages.

The thesis aims to study the cooperative principle in doctor-patient oral interaction by the $\mathrm{CP}$-directed analytical procedures for doctor-patient interaction. At the same time, the author analyzes the compliance and violation of cooperative principle for different purposes.

\subsection{Procedures and Data Collection of the Study}

Generally speaking, this study contains four steps, that is, corpus collection, corpus transcription, corpus translation and corpus analysis.

The first step of this study is collecting the corpus. The entire corpus used in this study was collected by the author in January and March, 2019, from four departments in outpatients in a Grade A hospital in Shenzhen. And to guarantee the representativeness of results, 20 cases of doctor-patient dialogues were randomly selected from 83 cases of recorded corpus according to proportion of each department.

The second and third steps of this study are transcribing and translating the corpus. For the convenience of further study, first of all, it is necessary to transcribe the recorded corpus into Chinese, and it also needs to be translated into English for the following specific case analysis. In the process of transcription, the author has to repeatedly listen to every detail of the recording in order to ensure the accuracy of the transcription. Both transcription and translation are very important. Although it is a time-consuming and hard work, the accurate transcription and translation will be critical to the following studies.

The fourth step of this study is analyzing the corpus. Specific case analysis will be carried out according to the selected dialogues. That is to say, list a specific example, explain the example, and draw the conclusion. 


\section{Results and Conclusion}

\subsection{Overall Results}

In the eighty-three doctor-patient oral interactions, doctors and patients obey the $\mathrm{CP}$ for most time, occupying nearly $77.6 \%$ of the time on average. In the four types of conversation, the author collected 13 conversations for diagnosis, 35 conversations for evaluation, 20 conversations for treatment and 15 conversations for consultation. Among them, conversations for consultation obey the $\mathrm{CP}$ most, followed by the conversations for evaluation, diagnosis and the conversations for treatment violate the CP least. The violation of each Maxim is shown in Graph 1.

The author selected 20 interactions according to the proportion of each department randomly. According to the 20 interactions, doctors violate the $\mathrm{CP}$ for 39 times and patients violate 41 times. Doctors violate the Maxim of Relevance the most, followed by the Maxim of Quantity, the Maxim of Manner and the Maxim of Quality. Every doctor in the study has violated the Maxim of Relevance while only two doctors violated the Maxim of Quality. On average, every male doctor violated the CP 4.4 times and every female doctor violated 4.25 times. Every doctor in respiratory department violated 1.5 times, every doctor in endocrinology department violated 4 times, every doctor in dermatology department violated 5 times and every doctor in plastic surgery department violated 7 times. Concrete statistic data is presented in Table 1.

Patients violated the Maxim of Quantity most, followed by the Maxim of Relevance, and the Maxim of Quality and Manner equaled the least. Patients for diagnosis violated the Maxim most, followed by the patients for evaluation, treatment and consultation.

Compared the two sets of statistic above (Table $1 \&$ Table 2), it is apparent that doctors are more likely to violate the Maxim of Relevance and patients are more likely to violate the Maxim of Quantity.

The author summed up the statistic and made Graph 2. From Graph 2, it would not be difficult to know that the Maxim of Quantity is violated most and the Maxim of Quality the least in both doctors and patient. The violation of the Maxim of Manner doesn't show any difference in doctors and patients.

\subsection{Analysis}

The analysis will be carried out based on different types of the doctor-patient oral interaction classified by the aim of the conversations. Here are some examples.

Example 1: A conversation for diagnosis

P: I am saying that, (I am, just the annual physical examination), my medical examination of recent years basically showed that my blood glucose is super high, (then), but I never take it matter. And the report of this year should be over 6. (是这样的, 我是, 就是每年体检, 然后, 就是, 我几年的体检基本都 是血糖过高, 然后, 以前也没太在意, 今年的应该也是 6 点几。) 


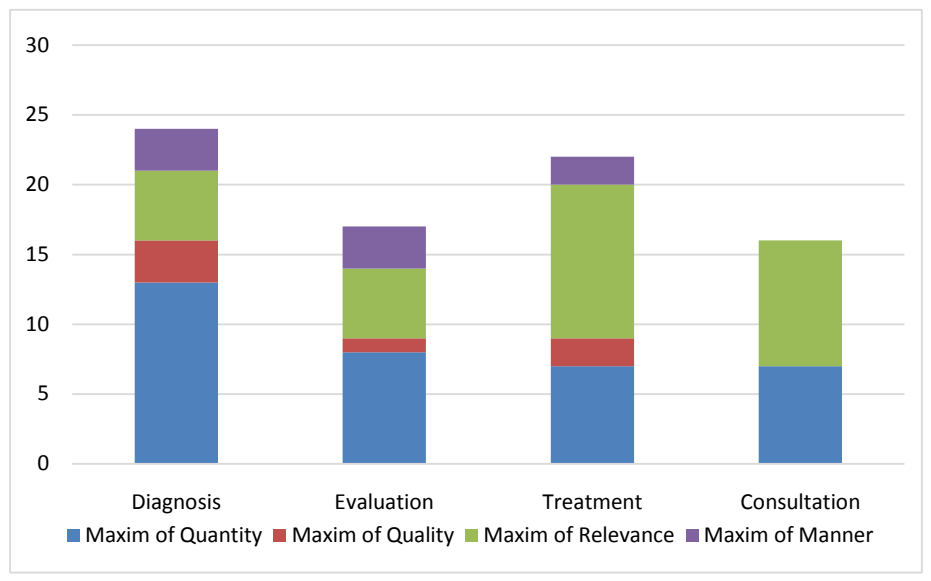

Graph 1. The distrubution of the violation of Maxim in 4 types.

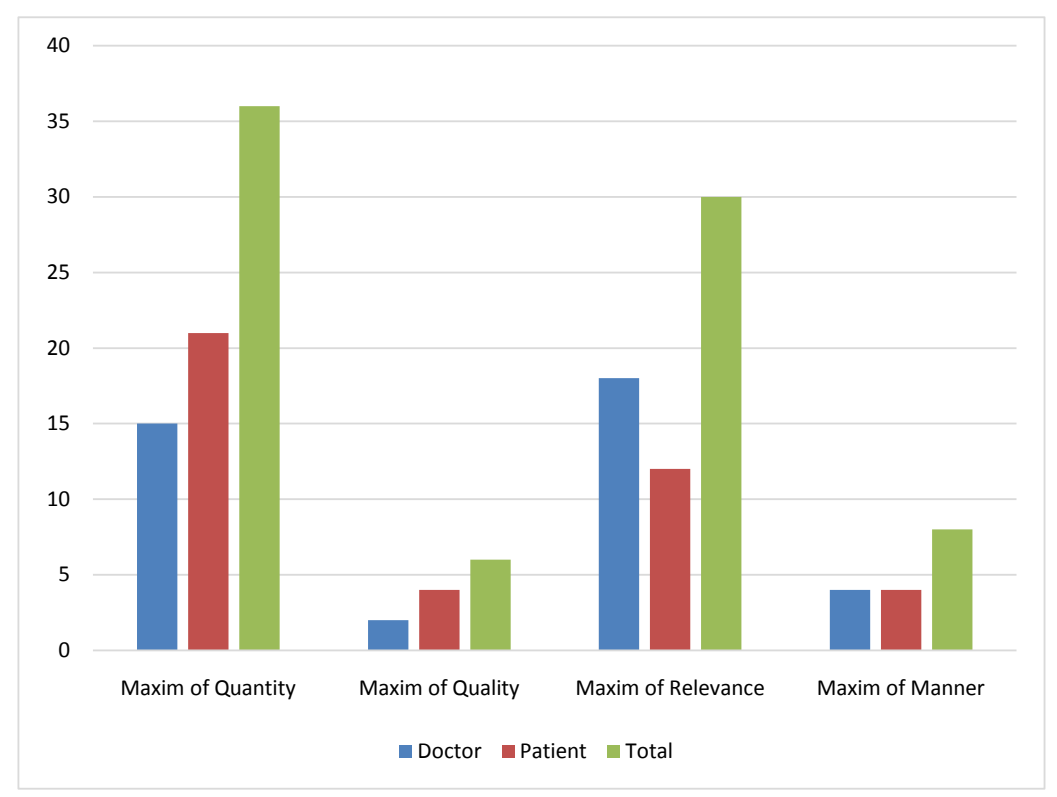

Graph 2. The comparison of doctors and patients violate the Maxim.

Table 1. The distrubution of doctor's violations of Maxim.

\begin{tabular}{ccccccc}
\hline \multicolumn{2}{c}{ Doctor Maxim } & Quantity & Quality & Relevance & Manner & Total \\
\hline $\begin{array}{c}\text { Respiratory } \\
\text { department }\end{array}$ & Male & 0 & 0 & 1 & 1 & 2 \\
& Female & 0 & 0 & 1 & 0 & 1 \\
Endocrinology & Male1 & 2 & 1 & 2 & 2 & 7 \\
department & Male2 & 1 & 0 & 1 & 0 & 2 \\
Fermatology & Male & 1 & 0 & 4 & 0 & 3 \\
department & Female & 3 & 0 & 2 & 0 & 5 \\
Plastic surgery & Male & 1 & 0 & 5 & 0 & 5 \\
department & Female & 5 & 1 & 1 & 0 & 6 \\
Total & & 15 & 2 & 18 & 4 & 39 \\
\hline
\end{tabular}


Table 2. The distrubution of patient's violations of Maxim.

\begin{tabular}{cccccc}
\hline Type Maxim & Quantity & Quality & Relevance & Manner & Total \\
\hline Diagnosis & 11 & 2 & 2 & 1 & 16 \\
Evaluation & 8 & 1 & 3 & 2 & 14 \\
Treatment & 1 & 1 & 5 & 1 & 8 \\
Consultation & 1 & 0 & 2 & 0 & 3 \\
Total & 21 & 4 & 12 & 4 & 41 \\
\hline
\end{tabular}

D: This is the report of 2014, 2015, 2016 and 2017. Is there someone who suffer from diabetes in your family members? (这是 14 年、15 年、1617 的。家里 有没有糖尿病的？)

P: Umm, my dad was found hyperglycemia after 50. (He didn't know before.) And it is hard to know if he has got the disease since his young age. (额, 我爸, 我爸是血糖高, 但他也是 50 多岁之后, 以前也不知道嘛, 不知道他年轻时候 有没有。)

Example 1 is a doctor-patient oral interactions of endocrinology department. The patient showed some symptoms of diabetes and he came to doctor to determine if he got a disease. The doctor read his medical examination report of recent years and asked him several questions for information and detect the disease. In Example 1, when the doctor asks the patient, Is there someone who suffer from diabetes in your family members? (家里有没有糖尿病的?) and the patient answers My dad was found hyperglycemia after 50. And it is hard to know if he has got the disease since his young age. (我爸是血糖高, 但他也是 50 多岁之后, 以前也不知道啉, 不知道他年轻时候有没有。) So the patient violates the Maxim of Quantity. He didn't answer the question of the doctor that if he has a family member with diabetes but said that his father suffered from hyperglycemia. Diabetes and hyperglycemia are two different terms to describe abnormal physical condition, but they are connected in some aspects, for example, diabetes may cause hyperglycemia. So it is likely that the patient didn't know the difference between the two terms or he didn't learn his father's disease exactly and he actually wanted to tell the doctor that his father may suffer from diabetes and has similar symptoms.

Example 2: A conversation for evaluation

D: Okay, what is your dose now? (好, 现在吃几片的药?)

P: Last time? You are not here last time. (上次? 你又没有在。)

D: Yeah, I mean how many pills do you take now? (对, 我说你现在吃几片 呐? )

P: (Now, I've taken it.) It's been half a year. (现在, 吃, 吃半年多了。)

D: I know. Do you still take the medicine now? (我知道, 你现在还有没有吃 药啊? )

P: Yes, I take medicine now, but it has run out. (现在我吃了, 没有药了。)

D: How long have you stopped the medicine? (停了多久啊?) 
P: I didn't stop. It was just reduced in the hospital of Pingdi. (没有停, 就在坪 地那里减了。)

D: Oh, it was reduce. So how many pills do you take now? (哦, 减了, 那现在 吃几片? )

P: One and a half pills. (一片半。)

In Example 2, when the doctor asks, What is your dose now? (现在吃几片的 药? ) the patient answers You are not here last time. (上次? 你又没有在。) So the patient violates the Maxim of Relevance. Interestingly, the patient finally tells the exact answer at the third time the doctor raises the same question and it cause the doctor to doubt that the patient has stopped taking medicine.

Example 3: A conversation for treatment

D: (There is no other way.) If you insist to remove it, there's nothing I can do but use laser. (The effect is) It causes least damage and leaves no trace. (那也没 办法, 你现在一定要搞那就是激光。效果最, 损伤最小的, 又不会留痕迹。)

P: No, I mean what if it grows again? (不是, 还会再长怎么办? )

$\mathrm{D}$ : Just the laser. (就激光扫。)

Example 3 is a doctor-patient oral interaction of plastic surgery department. Patients' major demand for plastic surgery department is to make them beautiful, so the symptoms of this department are actually people's lack of confidence in their lookout. Most patients come to the department directly asking for a surgery and the outpatient conversations are usually about surgery. In Example 3, the doctor tries to persuade the patient to undergo a laser treatment, and when the patient asks, No, I mean what if it grows again? (不是, 还会再长怎么办? ) the doctor answers Just the laser. (就激光扫。) So the doctor violates the Maxim of Relevance. The doctor thinks the laser is the best treatment for this patient and he wants to dispel any doubt of the patient. So, his implication is that you will be fine with the laser.

Example 4: A conversation for consultation

P: How many stitches would it be (to cut that)? (切掉那个那个要缝几针 呐? )

D: It is not important how many stitches it will be in plastic suturing. What matters is that we can suture it beautifully. (我们美容缝合你不要管缝几针, 这 个针, 缝几针都是次要的, 关键是缝漂亮。)

P: I know. I am just wondering if there will be scars left after the surgery. (我 知道, 就是缝了之后还有没有疮痕的? )

D: The scar could not be obvious. (这个疤痕呢, 不明显。)

In Example 4, the patient asks about the surgery, How many stitches would it be? (切掉那个那个要缝几针呐? ) and the doctor answers It is not important how many stitches it will be in plastic suturing. What matters is that we can suture it beautifully. (我们美容缝合你不要管缝几针, 这个针, 缝几针都是次要 的, 关键是缝漂亮。) The answer has a point but does not cooperate. The threads used in plastic surgeries is made of protein and can melt with tissues afterwards. So the number of stitches can not affect the prognosis of the surgery. For the unsatisfied answer the patient raises another question, I am just wondering if 
there will be scars left after the surgery. (就是缝了之后还有没有疤痕的?) and the doctor answers The scar could not be obvious. (这个疤痕呢, 不明显。) And the compliance of the answer is that it will probably leave a scar, and it will not be obvious.

\subsection{Conclusion}

From the corpus analysis and examples, it is found that a complete doctor-patient oral interaction in the outpatient department can be generally divided into 4 types that are the conversation for diagnosis, the conversation for evaluation, the conversation for treatment and the conversation for consultation. It is also found that there are differences between doctors and patients in compliance and violation of the Cooperative Principle.

In the conversation for diagnosis, the Maxim of Quantity is the most frequent to be violated and mostly violated by the patients while doctors prefer to violate the Maxim of Relevance. In the process of diagnosis, patients first state their symptoms, and then doctors ask some questions to learn about patients' physical condition. Doctors' questions often recall patients of their other symptoms, so the patients often say more about the questions and thus violate the Maxim of Quantity (Ji, Wang, \& Hu, 2018).

In the conversation for evaluation, the Maxim of Quantity is still the most frequent to be violated and mostly violated by the patients. When patients go to doctor for evaluation, doctors often let them exam some medical texts and study the result later. Like the process of diagnosis, doctors ask for patients' recent condition and violation is caused.

In the conversation for treatment, the Maxim of Relevance is the most frequent to be violated and mostly violated by the doctors. The treatment stage is usually raised by patients, so doctors are supposed to answer questions mainly. And compared to deny the proposal patients raised, doctors prefer to correct them directly, and in that condition, the Maxim of Relevance is violated.

In the conversation for consultation, only the Maxim of Relevance and the Maxim of Quantity are shown being violated in this study. Most of them are violated by doctors. Similarly, doctors answer questions in most time, and some questions may recall doctors of possible information. And the Maxim of Quantity is violated in that case.

In a word, through the analysis, it is found that both doctors and patients are likely to violate the four maxims of the Cooperative Principle. The violation of the Cooperative Principle will affect each type of the conversation. Some violations may help doctors understand their patients better and are beneficial for the doctor-patient relationship. But some violation will affect the development of the process, such as the extending of consultation time and the misunderstandings between doctors and patients.

Therefore, in order to ensure successful medical treatment and the better doctor-patient relationship the Cooperative Principle should be improved. 


\section{Discussion}

\subsection{Major Findings}

Through corpus analysis, it is found that there are differences between doctors and patients in compliance and violation of the Cooperative Principle of the doctor-patient interaction. Each type has different characteristics.

The following four kinds of situations often occur in the four types of doctor-patient oral interaction in outpatient departments: 1) When answering the doctor's question, most patients violate the Maxim of Quantity. They often provide excess information. 2) Many patients often violate the Maxim of Relevance, they sometimes relate something far from the doctors' question. 3) Both doctors and patients often comply with the Maxim of Manner. 4) Most doctors often comply with the Maxim of Quality and violate the Maxim of Relevance, especially the doctors in dermatology department and plastic surgery department. We found that instead of directly answering the patients' question doctors always provide other information to comply with the Maxim of Relevance.

\subsection{Practice Implications}

Through the CP-directed analytical procedures for doctor-patient interaction combined with the four conversational maxims of me the cooperative principle of doctor-patient interaction, the writer finds that the compliance of the $\mathrm{CP}$ does not always promote the conversation and the violation of the $\mathrm{CP}$ might have some positive effects on the conversation. Therefore, the Cooperative Principle has its limitation on conversation in outpatient department and new principle based on the CP should be built (West, 1984).

Health care organizations need to be aware that both the doctor and patient bring their own sociodemographic characteristics, attitudes and beliefs, expectations and communication styles to the medical encounter, affecting the delivery of medical services. The development of appropriate strategies for the clinical conversations will be crucial for the delivery of medical care.

\subsection{Limitations and Suggestions}

No research is perfect and mine is no exception. Improvements for future study are as follows.

First of all, due to the limited conditions, the corpus of this study is not very plentiful. So the corpus adopted in this study is only collected from four departments of the outpatients in one hospital. Future researchers can collect the corpus from other departments of the outpatients in more hospitals and more places nationwide. By doing so, the examples of the doctor-patient oral interaction will be more persuasive. The corpus is the basis of the study. The corpus collection work is of vital importance for the study. Therefore, in the future, the researchers need to pay more attention to collect enough corpus that is more representative.

In the next place, this thesis mainly studies the compliance and violation of 
the cooperative principle in doctor-patient oral interaction in outpatient departments. Future researchers can study other related issues, such as the difference between various levels and ages of doctors, the gender difference of doctors and patients, difference between patients of different ages and status and so on.

\section{Conflicts of Interest}

The authors declare no conflicts of interest regarding the publication of this paper.

\section{References}

Byrne, P., \& Long, B. (1976). Doctors Talking to Patients. London: HM-SO.

Den Boeft, M., Huisman, D., \& Morton (2017). Negotiating Explanations: Doctor-Patient Communication with Patients with Medically Unexplained Symptoms-A Qualitative Analysis. Family Practice, 34, 107-113. https://doi.org/10.1093/fampra/cmw113

Ji, C., Wang, X., \& Hu, Y. Y. (2018). Repetitions in Doctor-Patient Conversations of Reproductive Medicine. Medicine \& Philosophy (B), No. 6, 87-89.

Jin, J. (1999). The Use of Maxims for Cooperation in Chinese Medical Interviews. Health Communication, 11, 215-222. https://doi.org/10.1207/S15327027HC110304

Leech, G. N. (1983). Principles of Pragmatics. London: Longman.

Li, H. W. (2006). The Cooperative Principle and the Politeness Principle Showed in Clinical Conversation. Health Research, 26, 60-62.

Liu, X. B., Liu, Q., \& He, C. Q. (2008). A Review of Contemporary Research Abroad on Doctor-Patient Oral Interaction. Medicine \& Philosophy (A), No. 4, 19-21.

Wei, H. Y. (2015). A CP-Directed Study of Doctor-Patient Oral Interaction in Outpatient Departments. Beijing: North China Electric Power University.

West, C. R. (1984). Complications: Troubles with Talk between Doctors and Patients. Bloomington, IN: Indiana Univ. Press.

Zhang, X. Q. (2015). The Application of the Cooperation Principle in Doctor-Patient Conversation. Harbin: Northeast Agriculture University. 